\title{
Epistemic Slurs: A Novel Explicandum and Adequacy Constraint for Slur Theories
}

\section{Adam Patterson $^{1}$ (D)}

Received: 12 May 2019 / Accepted: 21 June 2020

(c) Springer Nature B.V. 2020

\begin{abstract}
I argue that there are slurs that are distinctly derogatory insofar as they only derogate their target's epistemic faculties or capacities qua group member. I call these slurs epistemic slurs. Given that slur theories should explain the derogatory nature of all slurs, any comprehensive slur theory should be able to explain the derogatory nature of the epistemic slurs. I argue, however, that two particular expressivist theories of slurs cannot explain their distinctive derogatory nature. The epistemic slurs thus constitute a novel explanatory problem for these expressivist slur theories. Yet I argue that a semantic theory of slurs, combinatorial externalism, can explain the distinctive derogatory nature of the epistemic slurs in which case these slurs constitute a novel explanatory advantage for combinatorial externalism. Whether the epistemic slurs constitute a novel explanatory problem or advantage for any other slur theories remains to be seen.
\end{abstract}

\section{Introduction}

Much philosophical work on slurs consists in attempts to give a theory to explain the derogatory nature of slurs. ${ }^{1}$ There are two broad kinds of such theories. On one type of slur theory slurs are derogatory because they have derogatory content. This is derogatory content that speakers either presuppose (e.g., Schlenker 2007), implicate (e.g., Williamson 2009; Whiting 2013; Vallée 2014), literally communicate in what is said (e.g., Hom 2008, 2012; Hom and May 2013; Hedger 2013), or express (e.g., Richard 2008; Croom 2011; Saka 2007; Hedger 2012; Jeshion 2013) when uttering a slur. There are also non-content-based theories of slurs according to which

1 Thanks to Tim Sundell, Clare Batty, James Lincoln, Colin Smith, Luvell Anderson, Michael Rieppel, Kevan Edwards, Byron Simmons, and Evelyn Hudson for repeated, helpful feedback and comments on earlier drafts of this paper.

Adam Patterson

apatters@syr.edu

1 Department of Philosophy, Syracuse University, 541 Hall of Languages, Syracuse, NY 13244, USA 
slurs are derogatory not because slurs (or their uses) communicate derogatory content but because slur uses violate edicts surrounding their usage Call slur theories that explain the derogatory nature of slurs by positing that slurs have content that is derogatory content-based theories of slurs (Anderson and Lepore 2013a, b). All slur theories have something in common: their adequacy is constrained by how well they can explain the derogatory nature of slurs.

In Sect. 2, I show that there are some slurs that are distinctively derogatory insofar as they derogate only their target's intelligence as a member of some identifiable group that is falsely stereotyped as being unintelligent. I call these slurs 'epistemic slurs'. I also show how the epistemic slurs differ from (and also are similar to) paradigmatic slurring terms such as 'chink' and what I call epistemic insults. In Sect. 3, I argue that several expressivist theories of slurs-hybrid expressivism and gesturalist expressivism, i.e., gesturalism (Hornsby 2001) — cannot explain the derogatory nature of the epistemic slurs. The epistemic slurs thus constitute a novel explanatory challenge for these slur theories. In Sect. 4, though, I argue that a semantic theory of slurs, combinatorial externalism $(\mathrm{CE}),{ }^{2}$ can explain the distinctive derogatory nature of the epistemic slurs. I summarize and conclude in Sect. 5.

\section{The Epistemic Slurs}

Consider the following three pairs of slurs:
(1) Nigger
(2) Spota
(3) Chink
(4) $\mathrm{Zip}^{3}$
(5) Button/dot-head
(6) Dip

According to The Racial Slur Database (2009), 'dip' is short for 'dumb Indian Punjab'. 'Zip' is short for 'zero intelligence potential'. 'Spota' is not short for anything, but it means 'dumb, inner-city African American'. So, the even-numbered slurs above specifically derogate the targeted individual's intellectual abilities or capacities. I call these slurs epistemic slurs. To characterize the epistemic slurs further let us compare and contrast them with their non-epistemic counterparts.

\subsection{Differences with Their Counterparts}

There are, at least, two differences between the epistemic slurs and their non-epistemic counterparts. The first is that the epistemic slurs, unlike their non-epistemic counterparts, in particular derogate the intellectual abilities of the individuals they target. But

\footnotetext{
2 This shorthand is Whiting's (2013).

3 This slur was featured in the movies Platoon and, more recently, Gran Torino.
} 
they don't just target these individuals as individuals. It would, for example, be odd for someone to say so-and-so is a zip but I am neutral with respect to the intelligence of Chinese persons. To use an epistemic slur is thus not simply to derogate the intellectual abilities of the targeted individual, it is also to target that individual as a member of some identifiable group that is falsely stereotyped as being unintelligent. To use an epistemic slur is also not to derogate both the target's intelligence and group membership without communicating something about the relation between the two. Otherwise calling someone a 'zip' would communicate the same thing that calling them a 'moronic Chink' communicates. If that were true, then competent slur users would plausibly not use epistemic slurs like 'zip'. They do. To use an epistemic slurs is to derogate the targeted individual's intellectual abilities because that individual belongs to a group that is stereotyped as being unintelligent. So, for example, for a speaker to call someone a 'zip' is to communicate that the target is unintelligent in virtue of belonging to a group that is stereotyped as being unintelligent (Chinese persons).

However, the odd-numbered slurs above do not derogate only the intellectual abilities of the targeted individual in virtue of belonging to some identifiable group that is falsely stereotyped as being unintelligent. So, for example, to call someone a 'chink' is not to derogate just one aspect of the targeted individual that the target exemplifies in virtue of being Chinese.

The difference between epistemic slurs and epistemic insults such as 'moron' and 'idiot' should now be clear. ${ }^{4}$ Epistemic insults are pejorative terms that derogate the intellectual abilities of their target but do not need to communicate anything about their target's membership to some identifiable group. Calling me an 'idiot', for example, does nothing to communicate my being unintelligent in virtue of my being Caucasian, only my being unintelligent. ${ }^{5}$ But epistemic slurs (along with their nonepistemic counterparts) do derogate their targets qua group members.

The second difference between epistemic slurs and their non-epistemic counterparts lies in their purported extensions. ${ }^{6}$ The extension of a slur is the set of persons that the slur purports to apply to. So, for example, while the extension of the racial slur (1) is the set of African-American persons, the extension of (2) is the set of those unintelligent African-American persons who are unintelligent in the ways that African-Americans stereotypically are. So, the extension of (2) is a subset of the extension of (1). The extension of (3) is the set of all Chinese persons. Yet the extension of (4) is a subset of the set of Chinese persons. The extension of (4) is the set of Chinese persons who are unintelligent in the ways that Chinese people stereotypically are. The epistemic slurs above thus have different extensions than their respective non-epistemic counterparts. ${ }^{7}$

\footnotetext{
4 Thanks to an anonymous referee for pushing me to clarify the distinction between epistemic slurs and epistemic insults.

5 Given footnote 34 in Copp (2001), both Copp and Bach would plausibly endorse this distinction.

${ }^{6}$ I say 'purported' because Hom and May (2013) argue that slurs have empty extensions. Henceforth when I say 'extension' I mean 'purported extension'.

7 That some slurs can have an extension that is the subset of the extension of another slur is familiar. To illustrate, consider the outdated slur for African American children 'pickaninny' and the slur 'nigger'. The extension of the former (the set of African-American children) is a subset of the extension of the latter (the set of African-Americans). Thanks to Luvell Anderson for these examples.
} 
These are but some of the ways in which the epistemic slurs differ from their counterparts. But this is not to say that the epistemic slurs and their odd-numbered, non-epistemic counterparts have nothing in common. They do.

\subsection{Similarities to Their Counterparts}

There are at least three important similarities between the epistemic slurs and their non-epistemic counterparts. The first is that the epistemic slurs exhibit certain features that are uncontroversially exhibited by slurs in general. Let us consider a few examples such as derogatory force, taboo, and embedding failure (Hom 2008): ${ }^{8}$

Derogatory Force For a speaker to use is a slur is for that speaker to forcefully communicate negative attitudes towards their target (Hom 2008).

This is to say that predicating a slur of someone is deeply derogatory and also more insulting than predicating common insults of them (Hom 2008, p. 426). So, for example, calling someone a 'chink' communicates forceful negative attitudes towards the target. Doing so is also far more insulting than calling that same person an 'asshole'. The same holds for 'zip'; calling someone a 'zip' is deeply derogatory and more insulting than merely calling him or her 'stupid' or 'a moron'. So, the epistemic slurs above exhibit derogatory force. ${ }^{9}$ The following is also true of epistemic slurs:

Taboo There are strict constraints governing the use of slurs if not outright prohibitions against their use (Hom 2008, 2010; Anderson and Lepore 2013a, b; Jeshion 2013).

That is, the use of a group-based slur is rarely, if ever, appropriate (Hom 2008, p. 427). Moreover, as Hom (2008) points out, taboos against the use of slurs often extends beyond their direct use to a myriad of situations including indirect speech reports, works of fiction, questions, etc. plausibly on the assumption that a slur use which breaks the taboo will cause some harm (Jay 2009, p. 153). The same holds for the epistemic slurs. Here is an example: A special education teacher in South Carolina wrote a memo to her colleagues wherein she reported that some students were self-identifying as 'retarded'. And for merely mentioning this slur, she was suspended. ${ }^{10}$ So, taboo is also true of epistemic slurs. The following is also true of the epistemic slurs:

\footnotetext{
8 They also plausibly exhibit others features that are exhibited by slurs in general—e.g., what Hom (2008, pp. 426-427) calls meaningfulness, linguistic appropriation, and derogatory autonomy. Moreover, like slurs in general the epistemic slurs exhibit neither infixation nor syntactic variability (cf. Hom 2010).

9 The same holds for other epistemic slurs like 'retard'.

${ }^{10}$ For more information, see "Suspended Teacher: Students call themselves idiot, retarded," The Seattle Times (April 28, 2016).
} 
Embedding Failure The derogatory force of a slur projects out of various forms of embedding constructions such as negations, indirect speech reports, antecedents of conditionals, etc. (Bolinger 2017; Hedger 2012; Camp 2013; Croom 2011; Anderson and Lepore 2013a).

To illustrate, consider the following two utterances:

(7) John said that Dave is a kike.

(8) If Dave is a kike, should we him buy his dinner?

Notice that (7) is still derogatory despite being an indirect speech report. And (8) is still derogatory despite the fact that the slur is embedded in the antecedent of a conditional. Similarly, for example, the following utterance is derogatory:

(9) Captain Harris said we have zips in the wire down here.

even though (9), like (7), is an indirect speech report. So, epistemic slurs also exhibit embedding failure.

The second important similarly between the epistemic slurs above and their non-epistemic counterparts is that both have neutral, i.e., non-pejorative, correlates (Langton et al. 2012; Hom 2008; Richard 2008; Vallée 2014; Camp 2013; Ashwell 2016; Bolinger 2017). ${ }^{11}$ A slur's non-pejorative correlative is a (relatively) neutral group term that picks out members of that slur's extension without thereby derogating them (Hom 2008, p. 427). The epistemic slurs above can actually share the accepted non-pejorative correlates with their non-epistemic counterparts. This is because, in general, any slur that has as its extension a subset of the extension of an established non-pejorative correlate is a slur that the non-pejorative correlate applies to. ${ }^{12}$ So, for example, (3)'s accepted non-pejorative correlate is the term 'Chinese'. Its extension is the set of all Chinese persons. The extension of (4) is, recall, the set of unintelligent Chinese persons who are unintelligent in the ways that Chinese people stereotypically are unintelligent. This is just a subset of the non-pejorative correlate's extension. So, the non-pejorative correlate 'Chinese' also applies to whomever (4) applies to in which case (4) and (3) can share a non-pejorative correlate. Any person that the slur 'zip' or 'chink' is true of is a person that the term 'Chinese' is true of.

A third way in which the epistemic slurs are similar to their non-epistemic counterparts is that both derogate their targets qua group member. So, to call one a 'chink' is to derogate them qua Chinese person. The same holds for the epistemic slurs as

\footnotetext{
11 For arguments to the contrary, see Ashwell (2016) and Croom (2015).

12 To illustrate, consider again 'pickaninny' and 'nigger'. Both have different extensions. The extension of the former is a subset of the latter's extension. Nevertheless, one can still use the neutral expression 'African-American' as a non-pejorative correlate to pick out without thereby derogating any African American person, regardless of their age. Thanks to Luvell Anderson for this point.
} 
well. To call one a 'zip' is to derogate them qua Chinese person. To call someone a 'nigger' or a 'spota' is to derogate the targeted individual qua African-American.

\subsection{An Objection: The Epistemic Slurs are not Genuine Slurs}

One might nevertheless object that in spite of these similarities the epistemic slurs above are not genuine slurs because genuine slurs can have the putative stereotypes associated with them reinforced without redundancy. To illustrate, consider the following:

(10) Ling is a chink and is dirty. ${ }^{13}$

The stereotype that Chinese persons are dirty is associated with the slur 'chink'. That stereotype is reinforced in (10). Yet (10) does not seem redundant or tautologous. This is because slurs like 'chink' "don't necessarily impute any specific properties to the group that they refer to" (Nunberg 2018). The epistemic slurs above certainly do impute specific properties to their targets. For 'zip' is just an acronym for 'zero intelligence potential'. Hence, the following attempt at stereotype reinforcement is redundant:

(11) Ling is a zip and is unintelligent.

So it looks like the epistemic slurs above cannot have their putative stereotypes associated with them reinforced without redundancy. This suggests that epistemic slurs are not genuine slurs after all. ${ }^{14}$

I reply that testing for stereotype reinforceability is not a way to determine whether a term is a slur. It is simply a test to determine whether a slur's derogatory content is a part of its linguistic meaning as semantic content or as a conversational implicature (Sadock 1978; Nunberg 2018). If the derogatory content of a slur is a part of the slur's linguistic meaning, then stereotype reinforcing would yield redundancies like in (11). That (11) is redundant is thus only a reason to think that the slur's derogatory content is a part of the slur's linguistic meaning and not a reason to think that the term 'zip' is not actually a slur.

\subsection{In Sum}

The epistemic slurs above, as we have just seen, derogate the intellectual abilities of the individuals they target because those individuals belong to identifiable, neutral groups that are stereotyped as being unintelligent. Their extensions are, moreover, subsets of the extensions of their non-epistemic counterparts. They can share

13 Thanks to an anonymous referree for this example.

14 Thanks to an anonymous referee for this objection. 
non-pejorative correlates with their counterparts. ${ }^{15}$ And they exhibit many uncontroversial features of slurs in general such as derogatory force, taboo, and embedding failure.

I will call any slur that derogates its target in virtue of belonging to some identifiable, neutral group a group-based slur. Racial slurs (such as 'coon') are a type of group-based slur. As are gendered slurs (such as 'cunt') and slurs concerning political affiliations (such as 'libtard'). I will, moreover, call any group-based slur that derogates a particular aspect of the targeted individual in virtue of the target's group membership an aspectual slur. Group-based slurs that do not derogate a particular aspect of the target I will call generic group-based slurs. Thus, the even-numbered slurs above are instances of a kind of aspectual, racial group-based slur that I call epistemic slurs. The odd-numbered slurs are, instead, rather generic, racial, groupbased slurs. The contemporary philosophical literature on slurs is almost exclusively concerned with the latter.

There might even be aspectual, group-based, non-epistemic slurs. Perhaps there is a slur that derogates a targeted individual's appearance or hygiene in virtue of belonging to some group that is stereotyped as being dirty and unkept (Bach 2014). Perhaps there is a slur that derogates a targeted individual's personality because that individuals belongs to a stereotypically boorish group. Insofar as theories of slurs seek to explain the derogatory nature of slurs, they should seek to explain the derogatory nature of any and all aspectual, group-based slurs. Such slurs might present a novel explanatory problem for the extant theories of slurs. But they might equally serve as a potential advantage for some of the extant theories of slurs over their competitors. ${ }^{16}$

In what follows, I will focus only on the even-numbered epistemic slurs above. This is not because I think that epistemic slurs are the only (or even the most) interesting kinds of slurs that have not been taken up in the contemporary philosophical literature. It is simply because I take them to be an important type of racial slur that any comprehensive theory of slurs should attempt to explain.

\section{A Few Expressivist Theories and the Epistemic Slurs}

I shall now argue that several of the extent content-based theories of slurs cannot explain the distinctive derogatory nature of the epistemic slurs above. The theories that I will discuss all maintain that a slur is derogatory because it has derogatory communicable content. Whether any other theories of slurs (be they contentbased or otherwise) can explain the distinctive derogatory nature of epistemic slurs remains to be seen.

\footnotetext{
15 These are not necessary conditions for when a pejorative term is an epistemic slur. These are merely features of the even-numbered slurs above, which are all instances of a type of group-based, aspectual, racial slur-epistemic slurs.

${ }^{16}$ This concession does not undercut the significance of what I am trying to point out. Even granting this concession the even-numbered slurs that I identify are still undiscussed and derogatory in a way that sets their derogatory nature apart from generic, racial (or gendered) group-based slurs in which case any adequate theory of slurs should explain them. It would be interesting to see how (and whether) the sundry slur theories can accommodate epistemic slurs.
} 


\subsection{The Expressivist Theories}

Expressivist, content-based theories of slurs are theories according to which a slur's derogatory content is not identical with or reducible to the slur's semantic, truth-apt content (Hom 2010). The slur's derogatory content is its expressive-or ineffable, non-truth-apt—content. Here, I discuss three expressivist views: pure expressivism, hybrid-expressivism, and gesturalism.

First, there is a pure expressivist theory of slurs (e.g., Hedger 2012). There is, on this view, a distinction between two types of communicable content (Kaplan 1997): there is descriptive content, which aims to aptly represent the world and is thereby truth-apt, and then there is expressive content, which instead consists in non-cognitive states like feelings or raw attitudes that are thus not truth-apt. Slurs, on this view, are a particular sub-category of pejoratives that lack any descriptive content and only have expressive content; they only express non-cognitive states. More precisely, the pure expressivist theory is this (Hedger 2012):

(PE) To predicate a slur, $D$, of someone, $x$, is to express nothing over and above some negative, non-cognitive attitude towards those who are members of the extensions of $D$ 's non-pejorative correlate, $C$.

To see how one could explain why slurs - and thus utterances involving them-are derogatory given this theory, consider the following utterance. It is a straightforward slurring predication:

(12) Devan is a kike.

Given the pure expressivist theory, one could analyze what a speaker communicates via (12) as follows:

\section{(12 $\left.{ }_{\mathrm{PE}}\right)$ Boo, Jewish persons!}

Thus, on the pure expressivist theory, slurs are derogatory because they communicate some negative, non-truth-apt expressive content that is absent from the slur's non-pejorative correlate. This also explains why (12) is derogatory; it involves a slur that communicates derogatory, expressive content. ${ }^{17}$

Second, there is the hybrid expressivist ${ }^{18}$ theory of slurs (e.g., Croom 2011, 2013; Boisvert 2008; Saka 2007, 143). On this view, there is also a distinction between expressive and descriptive content. Unlike the pure expressivist view, though, on the hybrid expressivist theory, in using a slur a speaker communicates both descriptive

\footnotetext{
17 The pure expressivist theory clearly cannot explain why epistemic slurs are distinctively derogatory. The reason is that on this theory slurs have no descriptive content whatsoever. Yet to felicitously use one of the epistemic slurs (or any slur) is to minimally communicate that the target belongs to some group. So, I will not discuss this view further. For further critique of the view, see Croom (2014).

18 I borrow this label from Camp (2013) and Bach (2014).
} 
and expressive content. More precisely, the hybrid expressivist theory is roughly this:

(HE) To predicate a slur, $D$, of someone, $x$, is to communicate that $x$ is member of the extensions of $D$ 's non-pejorative correlate, $C$, and to communicate some negative, non-cognitive attitude or feeling towards those who are members of the extension of $C .{ }^{19}$

To see how this theory could explain why slurs are derogatory, consider the following utterance:

\section{(13) Ling is a chink.}

On this view, one could analyze what speakers communicate with (13) as follows:

$\left(\mathbf{1 3}_{\mathbf{H E}}\right)$ Ling is Chinese. (And by the way: boo, Chinese people!) ${ }^{20}$

Thus, on the hybrid expressivist view, slurs are derogatory because in addition to descriptive content they communicate some negative, expressive content-in particular, some non-cognitive attitude or feeling - that is absent from the slur's nonpejorative correlate. ${ }^{21}$

Third, there is a gesturalist expressivist ${ }^{22}$ theory of slurs (e.g., Hornsby 2001). On this view, a slur communicates both descriptive and expressive content, but this expressive content is characterized as what Hom (2010) calls 'gestural' content. A slur's communicable, gestural content can be thought of as the same negative, communicable content that making a particular obscene gesture would communicate (Hornsby 2001, p. 104).

(GE) To predicate a slur, $D$, of someone, $x$, is to communicate that $x$ is a member of the extension of $D$ 's non-pejorative correlate, $C$, and to communicate negative, gestural content aimed at those who are members of the extension of $C$.

On this view, one could analyze (13) as follows:

$\left(\mathbf{1 3}_{\mathbf{G E}}\right)$ Ling is Chinese. (Extends middle finger towards Chinese persons).

Suppose that gestural content is just the expressive content that a slur communicates. On (GE), this expressive content is identical to the content that a derogatory

\footnotetext{
${ }^{19}$ I adapt this formulation from Hom (2010).

${ }^{20}$ I adapt this from Camp (2013, p. 332).

21 Ashwell (2016, p. 231) might call this a 'simple hybrid expressivism'.

22 This is Hom's (2010) label.
} 
gesture-like giving someone the middle finger in Western countries-communicates. ${ }^{23}$ So, on the (GE) view slurs are derogatory because they communicate negative, non-truth-apt gestural content.

We now have some theories to use as test cases. Henceforth I consider only hybrid expressivism and gesturalist expressivism. The question we face is this: can these theories capture the distinctly derogatory nature of the epistemic slurs; can they accommodate the observation that the epistemic slurs seem to be derogatory because they derogate the intellectual abilities of their targets as members of neutral, identifiable groups?

\subsection{A Novel Problem for Two Expressivist Theories of Slurs}

I will argue that the answer is 'no'. To illustrate, recall our hybrid expressivist and gesturalist expressivist theories:

(HE) To predicate a slur, $D$, of someone, $x$, is to communicate that $x$ is a member of the extension of $D$ 's non-pejorative correlate, $C$, and to communicate some negative, non-cognitive attitude or feeling towards those who are members of the extension of $C$.

(GE) To predicate a slur, $D$, of someone, $x$, is to communicate that $x$ is a member of the extension of $D$ 's non-pejorative correlate, $C$, and to communicate negative, gestural content aimed at those who are members of the extension of $C$.

And recall that we can analyze (13) on these theories as follows:

$\left(\mathbf{1 3}_{\mathrm{HE}}\right)$ Ling is Chinese. (Boo, Chinese people!)

$\left(\mathbf{1 3}_{\mathbf{G E}}\right)$ Ling is Chinese. (Extends middle finger lobbed at Chinese persons.) ${ }^{24}$

On both these theories, the term 'chink' is derogatory for the same reason: namely, that it communicates, in addition to its descriptive content, some negative, non-truth apt expressive content that is absent from the slur's non-pejorative correlate. This also explains why the any utterance employing the slurring term in (13) is derogatory. The utterance is derogatory because it involves a derogatory term.

Now, consider (13) but with the epistemic slur 'zip' used in lieu of 'chink':

(14) Ling is a zip.

\footnotetext{
23 Which gesture at issue with any given slur use is unclear. Moreover, Hom (2010, p. 171) is also correct that the distinction between (GE) and (HE) is murky. In fact, one might thus think that gesturalist expressivism is a just a kind of hybrid expressivist view. However, my only taxonomic claim here is this: (PE), (HE), and (GE) are all expressivist theories of slurs. I make no claim about how these theories related to each other beyond that.

24 I borrow talk of 'lobbing content' from Camp (2013, p. 323).
} 
How should we analyze (13) on hybrid expressivist and gesturalist expressivist theories? Recall, from Sect. 2.2 above, that the epistemic slurs can share a nonpejorative correlate with their counterparts. Given this, the analyses of (14) on these theories should look like this, respectively:

$\left(\mathbf{1 4}_{\mathrm{HE}}\right)$ Ling is Chinese. (And by the way: boo, Chinese people!)

$\left(\mathbf{1 4}_{\mathbf{G E}}\right)$ Ling is Chinese. (Extends middle finger lobbed at Chinese persons.)

Notice, however, that $\left(14_{\mathrm{HE}}\right)$ and $\left(14_{\mathrm{GE}}\right)$ are identical to $\left(13_{\mathrm{HE}}\right)$ and $\left(13_{\mathrm{GE}}\right)$, respectively. This means that on these theories, the epistemic slur 'zip' is derogatory for the same reason that the slur 'chink' is derogatory. The slur communicates negative expressive, non-truth-apt content.

Here is the problem. What makes epistemic slurs distinctly derogatory is that they derogate a particular aspect of the targeted individual qua group member. They distinctly derogate the target's intellectual abilities as a member of some group. But the expressive and gestural content in $\left(14_{\mathrm{HE}}\right)$ and $\left(14_{\mathrm{GE}}\right)$ does not capture anything about the target's intellectual abilities. So, on neither theory ${ }^{25}$ can one explain why the epistemic slurs above derogate only the targeted individual's intelligence qua group member.

\subsection{Objections and Responses}

Again: on our hybrid expressivist and gesturalist expressivist theories, what a speaker communicates via (14) is analyzed as $\left(14_{\mathrm{HE}}\right)$ and $\left(14_{\mathrm{GE}}\right)$, respectively. These analyses cannot be used to explain why epistemic slurs are distinctly derogatory; they derogate the intellectual abilities of the targeted individual qua group member. Yet the communicable content in both analyses that explains why slurs are derogatory-the slur's expressive content—contains nothing about the target's intelligence. Neither does the slur's descriptive content.

This naturally suggests a way for a proponent of either theory to respond. She can put some negative content about the target's intellectual abilities qua group member somewhere in slur's communicable content. Next, I show what the analysis of (14) would look like on these theories if negative content about the speaker's intelligence were (1) in both the slur's descriptive and expressive content, (2) only in its descriptive content, or (3) only in its expressive content. I then argue that these analyses cannot adequately explain the derogatory nature of epistemic slurs.

\footnotetext{
25 Note that (HE) is a characterization of a particular, simple hybrid expressivist view — not a characterization of the core commitment of all hybrid expressivist views. The same will hold for the combinatorial externalist (CE) theory, which will be introduced in Sect. 4. (CE) is not expressive of the core commitment of all semantic theories of slurs. So, my arguments that the (HE) and (CE) views cannot explain epistemic slurs is not to say that no hybrid expressivist or combinatorial externalist view can explain the epistemic slurs. Whether more nuanced and sophisticated views can explain the epistemic slurs above remains to be seen. Moreover, if other such views can then this should be shown. For if other views can explain the distinctive derogatory nature of epistemic slurs, these views will have an explanatory advantage over the (CE), (GE), and (HE) views.
} 


\subsubsection{Negative Epistemic Content Everywhere}

First, suppose that on our hybrid expressivist and gesturalist expressivist theories the negative content about the targeted individual's intelligence qua group member were located in both the slur's descriptive and expressive content. Then, on these views, (14) might be analyzed as follows:

(14.1 $\mathbf{H E}_{\mathrm{HE}}$ Ling is a Chinese person who is unintelligent in the ways that Chinese people stereotypically are. (And by the way: boo, Chinese people who are unintelligent in the ways that Chinese people stereotypically are!)

(14.1 $\mathbf{G E}_{\text {GE }}$ Ling is a Chinese person who is unintelligent in the ways that Chinese people stereotypically are. (Traces small circles in their air near one's temple aimed at Chinese people who are unintelligent in the ways that Chinese people stereotypically are.)

These analyses are problematic because they make the explanation of why 'zip' is derogatory overdetermined. On $\left(14.1_{\mathrm{HE}}\right)$ and $\left(14.1_{\mathrm{GE}}\right)$, the epistemic slur is derogatory because the slur has both derogatory expressive and derogatory descriptive content. Yet the core commitment of each view is that a slur's derogatory nature is solely tied to the slur's derogatory, expressive content. ${ }^{26}$ This is thus the only content that should explain why 'zip' is derogatory. Yet it is not on $\left(14.1_{\mathrm{HE}}\right)$ and $\left(14.1_{\mathrm{GE}}\right)$. So, to endorse $\left(14.1_{\mathrm{HE}}\right)$ is to eschew one's commitment to hybrid expressivism. To endorse $\left(14.1_{\mathrm{GE}}\right)$ is to give up on gesturalist expressivism.

\subsubsection{Negative Epistemic Content Only in Expressive Content}

Second, suppose that on our hybrid expressivist and gesturalist expressivist theories the content about the targeted individual's intelligence were located only in the slur's expressive content. Then (14) might be analyzed like this, respectively:

(14.2 ${ }_{\mathrm{HE}}$ ) Ling is Chinese. (And by the way: boo, Chinese people who are unintelligent in the ways that Chinese people stereotypically are!)

$\mathbf{( 1 4 . 2}_{\mathbf{G E}}$ ) Ling is Chinese. (Traces small circles in their air near one's temple aimed Chinese people who are unintelligent in the ways that Chinese people stereotypically are.) ${ }^{27}$

These initially seem plausible. And they avoid the overdetermination objection to $\left(14.1_{\mathrm{HE}}\right)$ and $\left(14.1_{\mathrm{GE}}\right)$. This is because 'zip' now only has derogatory expressive content. The derogatory content about the target's intelligence, on $\left(14.2_{\mathrm{HE}}\right)$ and $\left(14.2_{\mathrm{GE}}\right)$, is not found in both aspects of its communicable content.

\footnotetext{
26 They disagree only about how this content is characterized.

${ }^{27}$ Here the analysis involves an epistemically-loaded gesture. Thanks to James Lincoln and Colin Smith for this example.
} 
Nevertheless, these analyses are still problematic for two reasons. The first reason is that the purported expressive content in both of these analyses is plausibly nonexpressive content, for expressive content usually exhibits the following:

Descriptive Ineffability There is usually no adequate descriptive paraphrase for expressive content in non-expressive terms (Potts 2007, p. $166,176)$.

The expressive content of both $\left(14.2_{\mathrm{HE}}\right)$ and $\left(14.2_{\mathrm{GE}}\right)$, however, does not exhibit descriptive ineffability. There are descriptive paraphrases of $\left(14.2_{\mathrm{GE}}\right)$ 's gestural content that can be given in non-expressive terms. Here is one: Ling is a stupid Chinese person. ${ }^{28}$ There are also descriptive paraphrases of $\left(14.2_{\mathrm{HE}}\right)$ 's content. In fact, one can give the same descriptive paraphrase in non-expressive terms of the purported expressive content in $\left(14.2_{\mathrm{HE}}\right)$ that one can give for the purported expressive content in $\left(14.2_{\mathrm{GE}}\right)$.

The second reason that $\left(14.2_{\mathrm{HE}}\right)$ and $\left(14.2_{\mathrm{GE}}\right)$ are problematic analyses is this. On both analyses, a speaker's utterance of (14) does not communicate that Ling is an unintelligent Chinese person. It merely communicates (literally in what is said) that Ling is Chinese. Yet on both analyses a speaker's utterance of (14) expresses some negative attitude that the speaker has only towards unintelligent Chinese persons. This is problematic. For if a speaker's utterance of (14) does not communicate that Ling is a member of the group that the speaker expresses negative attitudes towards, then it is felicitous for the speaker to say this: Ling is a zip but I am not saying anything bad about Ling's intelligence as a Chinese person. However, as we saw in Sect. 2.1 to call someone a 'zip' is communicate that the target is unintelligent in virtue of belonging to a group falsely stereotyped as being unintelligent (Chinese persons).

\subsubsection{Negative Epistemic Only in Descriptive Content}

Suppose finally that, on these theories, the content about the targeted individual's intelligence is located solely in the slur's descriptive content. Then (14) might be analyzed as follows:

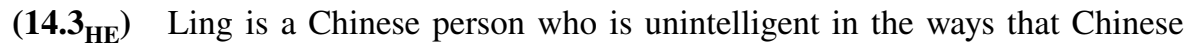
people stereotypically are. (And by the way: boo, Chinese persons!)

(14.3 GE $_{\text {G }}$ Ling is a Chinese person who is unintelligent in the ways that Chinese people stereotypically are. (Traces small circles in their air near one's temple aimed at Chinese persons.)

${ }^{28}$ Thanks to an anonymous referee for this example. 
These analyses also dodge the overdetermination problem because the derogatory content concerning the target's intelligence qua group member is found only in one part of the slur's communicable content.

These analyses are, nevertheless, still problematic for they would make a slur's expressive content explanatorily idle. On both of these expressivist theories, the derogatory nature of a slur is bound only to its expressive, derogatory content. This content alone explains why slurs (and slurring utterances) are derogatory. Yet on $\left(14.3_{\mathrm{HE}}\right)$ and $\left(14.3_{\mathrm{GE}}\right)$ it is only the slur's descriptive content that explains why 'zip' is distinctively derogatory. This is to say that the slur's communicable content that should explain why 'zip' derogates only the target's intellectual abilities qua group member on these theories, the slur's expressive content, does not. To endorse $\left(14.3_{\mathrm{HE}}\right)$ is to eschew one's commitment to hybrid expressivism. To endorse $\left(14.3_{\mathrm{GE}}\right)$ is to give up on gesturalist expressivism.

In sum, on neither of these theories can one give a plausible explanation of the distinctive derogatory nature of epistemic slurs. The epistemic slurs above thus constitute a novel explanatory problem for these particular expressivist theories of slurs. ${ }^{29}$ Next, I examine whether a semantic theory of slurs can do any better.

\section{Combinatorial Externalism and Epistemic Slurs}

\subsection{Combinatorial Externalism}

On the combinatorial externalist theory of slurs (CE), a slur is derogatory because it has derogatory, semantic (truth-conditional) content (Hom 2008).

(CE) To predicate a slur, $D$, of someone, $x$, is to literally communicate in what is said that $x$ is a member of the extension of $D$ 's non-pejorative correlate, $C$, and in virtue of being a member of the extension of $C, x$ has negative properties stereotypically associated with belonging to the extension of $C$ and so ought to be subject to some discriminatory practices.

The semantic content of a slur on (CE), as we can see, consists in a combination of both descriptive and normative properties-hence the name combinatorial externalism. Hom's framework for specifying a slur's semantic content (SC) looks like this:

$\left(\mathbf{S C}_{\text {Schema }}\right) \quad x$ is a member of the extension of a slur, $D$,'s non-pejorative correlate, $C$, and ought to be subject to a variety of racist, deontic prescriptions, $\mathrm{p}^{*}{ }_{1}+\ldots+\mathrm{p}^{*}{ }_{\mathrm{n}}$, because of having the negative properties $\mathrm{d}^{*}{ }_{1}+\ldots$ $+\mathrm{d}^{*}{ }_{\mathrm{m}}$, associated with belonging to the extension of $C$, in virtue of being a member of C's extension (Hom 2008).

\footnotetext{
29 That these arguments apply to both of these theories should come as no surprise: for, as I mentioned in footnote 25 above, it seems plausible to think of gesturalist expressivism as a variant of hybrid expressivism.
} 
So, the meanings of slurs can be expressed by some complex predicate that fits said schema. More concretely, Hom (2008) instantiates this schema for the slur 'chink' as follows:

$\left(\mathbf{S C}_{\text {chink }}\right) \quad x$ is Chinese and ought to be subject to exclusion from workplace advancement, and ought to be subject to higher college admission standards, and ..., because of being slanty-eyed, and devious, and ..., in virtue of being Chinese.

Importantly, however, on the (CE) view a slur's semantic content is not causally determined by the speaker's psychological states. Rather, it is determined externally via the structural, racist ideology and practices of racist institutions (Hom 2008) hence the name combinatorial externalism. ${ }^{30}$

\subsection{A Novel Advantage of (CE)}

One can plausibly explain the distinctive derogatory nature of the epistemic slurs on combinatorial externalism. To see why, as before, let us first examine how we might analyze and explain the derogatory nature of an utterance that does not involve an epistemic slur given the combinatorial externalist theory. Recall the following:

\section{(13) Ling is a chink.}

How would this get analyzed? We have a specification of the meaning of 'chink' already:

$\left(\mathbf{S C}_{\text {chink }}\right) \quad x$ is Chinese and ought to be subject to exclusion from workplace advancement, and ought to be subject to higher college admission standards, and ..., because of being slanty-eyed, and devious, and ..., all because of being Chinese.

We might then analyze (13) like as follows:

$\left(\mathbf{1 3}_{\mathbf{C E}}\right)$ Ling is Chinese; and ought to be subject to exclusion from workplace advancement, and ought to be subject to higher college admission standards, and ..., because of being slanty-eyed, and devious, and ..., all because of being Chinese.

Here is a question: how is the meaning of 'chink' that $\left(\mathrm{CE}_{\text {chink }}\right)$ presents derived from and supported by an external, racist institution?

\footnotetext{
${ }^{30}$ As Sennet and Copp (2015, p. 1084) rightly notice, this is what distinguishes (CE) from Hom's later attempt of a semantic theory of slurs (Hom and May 2013).
} 
The proponent of the combinatorial externalist theory might provide the following explanation. The term 'chink' is a generic, racial, group-based slur. It is a slur that does not derogate some particular aspect of the targeted individual. So, on the (CE) view the meaning of 'chink', which is specified by $\left(\mathrm{SC}_{\text {chink }}\right)$, is derived from (and supported by) the general racist ideology and practices of some external institution of racism towards Chinese persons that the slur stands in the appropriate relation to (Hom 2008, p. 431). This is to say that the general racist ideology and practices of an institution of racism towards Chinese persons contribute to the meaning of 'chink'. This is why, on the (CE) theory, calling someone a 'chink' ascribes to them many and sundry types of negative properties and deontic prescriptions.

Analyzing (13) as such provides a straightforward explanation for why, on (CE) theory, the slur 'chink' is derogatory: it has derogatory semantic content; to use the slur is literally to communicate in what is said that the target ought to be subject to some particular discriminatory practices for being devious, being slanty-eyed, etc. in virtue of the fact that the target is Chinese (Hom 2010, p. 180).

Now, let us see how we might analyze an utterance that does not involve an epistemic slur on combinatorial externalism. Recall the following:

(14) Ling is a zip.

We might analyze (14) as follows: ${ }^{31}$

$\left(\mathbf{1 4}_{\mathbf{C E}}\right)$ Ling is Chinese and ought to be subject to testimonial censure, and..., because being unintelligent in the ways that Chinese people are stereotypically unintelligent, all because of being Chinese.

The following presents the semantic content of 'zip' on $\left(14_{\mathrm{CE}}\right)$ :

$\left(\mathbf{S C}_{\mathbf{z i p}}\right) \quad x$ is Chinese and ought to be subject to testimonial censure, and..., because of being unintelligent in the ways that Chinese people are stereotypically unintelligent, all because of being Chinese.

Suppose that this schematization of the semantic content of 'zip' is right. ${ }^{32}$ How would the meaning of 'zip' be derived from and supported by an external, racist institution?

The proponent of (CE) might attempt to explain this like this: the slur 'zip' is not a generic, racial, group-based slur but is rather an aspectual, racial, group-based slur. So, on (CE) view, the meaning of 'zip' is derived from (and supported by) a

\footnotetext{
31 Thanks to Tim Sundell for this suggestion.

32 This is dubious, though. On Hom's (2008) view, the meaning slur 'zip' is schematized as complex predicate that minimally involves deontic prescriptions. Yet the meaning of 'zip' lacks any such prescriptions because 'zip' just means 'zero intelligence potential'. For 'zip' is an acronym for 'zero intelligence potential'. So, Hom's view cannot accurately represent the meaning of the slur 'zip'. Nor can the view accurately represent the meaning of any other slur that is an acronym.
} 
particular aspect of that same external, racist institution's ideology and practicesonly those bits of ideology and practices that concern the intelligence of Chinese persons. This is to say that only those bits of ideology and practices that concern the intelligence of Chinese persons contribute to the meaning of 'zip'. This explains why on $\left(14_{\mathrm{CE}}\right)$ calling someone a 'zip' ascribes to them but one particular negative property about their intelligence (being unintelligent).

Analyzing (14) as such allows the proponent of (CE) an easy explanation for why 'zip' is derogatory in general. The slur has derogatory semantic content. The analysis also allows the proponent of (CE) an easy explanation for why 'zip' is distinctively derogatory as well. The only semantic content that the term has concerns the target's intelligence qua group member.

\section{Conclusion}

I have argued that there are epistemic slurs which only derogate their targeted individual's intelligence as a member of some identifiable, neutral group that is stereotyped as being unintelligent. The epistemic slurs are a type of aspectual, racial, group-based slurs that are similar to and yet importantly different from their nonepistemic counterparts, which are generic, racial group-based slurs. Since the epistemic slurs are derogatory in a distinctive way, any slur theory of slurs should be able to explain their derogatory nature. I have argued that two particular expressivist theories of slurs cannot plausibly explain the derogatory nature of the epistemic slurs. However, I have argued that a semantic theory of slurs can explain the derogatory nature of the epistemic slurs. It remains to be seen whether epistemic slurs constitute a novel explanatory problem or a novel explanatory advantage for other slur theories.

\section{References}

Anderson, L., \& Lepore, E. (2013a). Slurring words. Nous, 47, 25-48.

Anderson, L., \& Lepore, E. (2013b). What did you call me? Slurs as prohibited words. Analytic Philosophy, 54, 350-363.

Ashwell, L. (2016). Gendered slurs. Social Theory and Practice, 42, 228-239.

Bach, K. (2014). Loaded words: On the semantics and pragmatics of slurs. In American Philosophical Association Pacific Division Eighty-Eighth Annual Meeting, 19 April. San Diego: The American Philosophical Association.

Boisvert, D. (2008). Expressive-assertivism. Pacific Philosophical Quarterly, 89, 169-203.

Bolinger, R. (2017). The pragmatics of slurs. Nous, 51, 439-462.

Camp, E. (2013). Slurring perspectives. Analytic Philosophy, 54, 330-349.

Copp, D. (2001). Realist-expressivism: A neglected option for moralist realism. Social Philosophy and Policy, 18, 1-43.

Croom, A. M. (2011). Slurs. Language Sciences, 33, 343-358.

Croom, A. M. (2013). How to do things with slurs: Studies in the way of derogatory words. Language \& Communication, 33, 177-204.

Croom, A. M. (2014). Remarks on "The semantics of racial slurs". Linguistic and Philosophical Investigations, 13, 11-32.

Croom, A. M. (2015). The semantics of slurs: A refutation of referentialism. Ampersand, 2, 30-38. 
Hedger, J. (2012). The semantics of racial slurs: Using Kaplan's framework to provide a theory of the meaning of derogatory epithets. Linguistic and Philosophical Investigations, 11, 74-84.

Hedger, J. (2013). Meaning and racial slurs: Derogatory epithets and the semantics/pragmatics interface. Language \& Communication, 33, 205-213.

Hom, C. (2008). The semantics of racial epithets. Journal of Philosophy, 105, 416-440.

Hom, C. (2010). Pejoratives. Philosophy Compass, 5, 164-185.

Hom, C. (2012). A puzzle about pejoratives. Philosophical Studies, 159, 383-405.

Hom, C., \& May, R. (2013). Moral and semantic innocence. Analytic Philosophy, 54, 293-313.

Hornsby, J. (2001). Meaning and uselessness: How to think about derogatory words. Midwest Studies in Philosophy, 25, 128-141.

Jay, T. (2009). The utility and ubiquity of taboo words. Perspectives on Psychological Science, 4, 153-161.

Jeshion, R. (2013). Expressivism and the offensiveness of slurs. Philosophical Perspectives, 27, 307-335.

Kaplan, D. (1997). The meaning of ouch and oops. The Howison Lecture in Philosophy. Berkeley: UC Berkeley. Retrieved April 9th, 2015. https://www.youtube.com/watch?v=iaGRLlgP16w.

Langton, R., Haslanger, S., \& Anderson, L. (2012). Language and race. In G. Russell \& D. Fara (Eds.), The Routledge companion to philosophy of language (pp. 753-767). New York: Routledge.

Nunberg, G. (2018). The social life of slurs. In D. Fogal, D. Harris, \& M. Moss (Eds.), New work on speech acts (pp. 237-295). Oxford: Oxford University Press.

Potts, C. (2007). The expressive dimension. Theoretical Linguistics, 33, 165-198.

Racial Slur Database. (2009). Retrieved Februrary, 2015. http://www.rsdb.org.

Richard, M. (2008). When truth gives out. Oxford: Oxford University Press.

Sadock, J. M. (1978). On testing for conversational implicature. In P. Cole (Ed.), Syntax and semantics (pp. 281-297). Cambridge: Academic Press.

Saka, P. (2007). How to think about meaning. Dordrecht: Springer.

Schlenker, P. (2007). Expressive presuppositions. Theoretical Linguistics, 33, 237-245.

Sennet, A., \& Copp, D. (2015). What kind of mistake is it to use a slur? Philosophical Studies, 172, 1079-1104.

Vallée, R. (2014). Slurring and common knowledge of ordinary language. Journal of Pragmatics, 61, 78-90.

Whiting, D. (2013). It's not what you said, it's the way you said it: Slurs and conventional implicatures. Analytic Philosophy, 54, 364-377.

Williamson, T. (2009). Reference, inference and the semantics of pejoratives. In J. Almog \& P. Leonardi (Eds.), The philosophy of David Kaplan (pp. 137-159). Oxford: Oxford University Press.

Publisher's Note Springer Nature remains neutral with regard to jurisdictional claims in published maps and institutional affiliations. 